\title{
Is housing a public health issue? A survey of directors of public health
}

\author{
Paul Roderick, Christina Victor, James Connelly
}

\begin{abstract}
Objective-To determine the views of directors of public health on the importance of housing for public health and their departments' and health authorities' participation in housing issues.

Design-Postal self administered questionnaire survey.

Setting-All district health authorities in England and health boards in Wales, Scotland, and Northern Ireland.

Subjects-All 221 district directors of public health in England and chief administrative medical officers in Wales, Scotland, and Northern Ireland.

Main outcome measure-Response to questionnaire consisting of fixed and open ended questions on housing issues.
\end{abstract}

Results-The response rate was $89 \%(196 / 221)$. Housing was perceived as a major health problem by $33 \%(65 / 196)$ of directors. Positive responses were most likely from inner city districts. In 47\% (93/196) of departments there was a formal time commitment to housing issues with a median time of one session/ week (range one per month to 10 per week). The main function was allocation of medical priority for public sector rehousing. Overall, $73 \%$ (144/196) reported some participation in this process. Reported participation in joint care planning and links with non-statutory housing organisations were uncommon. 53\% (104/196) of directors had included housing issues in their annual health report. In $16 \%$ (32/196) of districts specific services for the homeless had been set up.

Conclusions-Although concern about the impact of current housing policy on public health was shown by a substantial number of directors, the main activity was still allocation of medical priority despite a background of increasing housing need and homelessness. The underlying need is for greater advocacy to produce a healthy housing policy for all, and the annual public health report could be used to promote this objective.

Epidemiology and Medica Care Unit, Northwick Park Hospital, Harrow,

Middlesex HA1 3UJ

Paul Roderick, MFPHM, visiting worker

James Connelly, MFPHM, visiting worker

\section{Department of Public}

Health, St Mary's Hospital, London W2 1NY

Christina Victor, PHD, director, public health research unit

Correspondence to: Dr Roderick.

$B M \mp$ 1991;302:157-60
The number of local authority "new starts," previously the mainstay of socially affordable housing, has fallen and neither the private sector nor housing associations have been able to fill the shortfall. This has contributed to the rise in numbers of both the single roofless and the so called "temporary homeless." ${ }_{6}$ The last are often placed in unsuitable accommodation, such as bed and breakfast hotels. Moreover, vulnerable groups in the community who have special housing needs, such as the frail elderly and some mentally ill people (especially long stay patients discharged from institutions), are increasing in size. This mismatch between supply and demand will deteriorate further in the 1990s; it is estimated that 3.2-4 million homes need to be added to current housing stock if all households are to have an adequate home. ${ }^{5}$ Housing policy is therefore an area of interest for those seeking to improve public health. Morris has called for a greater contribution of the medical profession in highlighting the national problem of inadequate housing. ${ }^{7}$ Moreover, advocacy for health promoting housing, by doctors and health authorities, is stated in target 7.1 of the WHO's health principles of housing: "Improvement of the health aspects of housing requires active leadership and informed advocacy by health authorities at all levels." "Present public health doctors now bear the responsibility for identifying the health needs of their local population and are expected to produce an annual health report which targets health issues of local concern..$^{10} \mathrm{We}$ therefore report the results of a survey which determined the current activity of public health medicine departments in local housing issues. It formed part of the work programme of the Faculty of Public Health Medicine's working party on housing and health.

\section{Methods}

In October 1989 a specially designed self administered questionnaire was sent to all directors of public health (one in each district health authority in England) and all chief administrative medical officers within the health boards of Wales, Scotland, and Northern Ireland. A second questionnaire was sent to nonresponders in December 1989.

The questionnnaire consisted of fixed and open ended questions covering six main topics. (1) Was housing considered to present a major health problem in the district-if so, by whom and in what way? (2) What was the role and time commitment to housing issues of the director of public health, chief administrative medical officer, and their staff? (3) Were housing issues included in the annual health report? (4) Did the department have links with other housing agencies? (5) Did the health authority provide special services for the homeless? (6) Was there a local health for all or healthy city group? Respondents were asked to classify their districts as inner city, suburban, mixed urban, urban-rural, or rural. 
Apart from the frequency distribution of the responses to the questions several associations were analysed using the $\chi^{2}$ test.

\section{Results}

Overall, 89\% (196/221) of questionnaires were returned; those not responding were evenly distributed across the regions and types of district.

Housing and the health of the local populationOverall, 48\% (94/196) of the respondents reported that housing was regarded as a major health problem in their district. In 33\% (65/196) the directors of public health or chief administrative medical officers stated that this was their view. Positive responses were more likely in inner city $(83 \%)$ or urban districts $(58 \%)$ (table I). Table II shows that the main problems were poor housing conditions $(51 \%)$ and lack of housing for groups with special needs $(21 \%)$.

TABLE I-Replies to question: "Is housing perceived as a major problem?" by respondents from each type of district

\begin{tabular}{lccc}
\hline & \multicolumn{2}{c}{ No (\%) of respondents replying } & \\
\cline { 2 - 3 } Type of district & Yes & No & Total \\
\hline Rural & $11(26)$ & $31(74)$ & 42 \\
Suburban & $6(33)$ & $12(67)$ & 18 \\
Mixed urban & $43(58)$ & $31(42)$ & 74 \\
Urban-rural & $19(48)$ & $21(52)$ & 40 \\
Inner city & $15(83)$ & $3(17)$ & 18 \\
\hline Total & $94(49)$ & $98(51)$ & 192 \\
\hline
\end{tabular}

$\chi^{2}=23 \cdot 7, \mathrm{df}=4, \mathrm{p}<0 \cdot 01$.

${ }^{\star}$ Four respondents did not reply to this question.

TABLE II-Reasons for housing being major problem given by 94 respondents who thought it was

\begin{tabular}{lc}
\hline Reason & $\begin{array}{c}\text { No (\%) of } \\
\text { respondents }\end{array}$ \\
\hline Effect of poor housing on health & $48(51)$ \\
Housing of special groups & $20(21)$ \\
As a marker of social deprivation & $16(17)$ \\
Homelessness & $13(14)$ \\
Reduced access to services & $5(5)$ \\
\hline Total $^{\star}$ & 102 \\
\hline
\end{tabular}

^Some respondents gave more than one reason.

Formal commitment to housing issues-In 47\% (93/196) of districts a member of the public health medicine department had a regular formal sessional commitment to housing problems; an additional 16 districts specified that some time was spent on such issues, although it did not constitute a formal commitment. The time allocated to housing issues varied from one session each month to 10 each week with a median of one each week (table III). The predominant function of these sessions was to allocate medical priority for rehousing by local authorities. This was reported by $87 \%(95 / 109)$ of those with a regular commitment and by $73 \%(144 / 196)$ of the whole sample. The input varied from providing advice on policy or difficult cases to undertaking all individual assessments, including home visits in some cases. Participation in other housing issues, such as joint care planning with local authorities relevant to housing (reported in 15 districts), was uncommon.

Inclusion of housing issues in the annual public health report-Overall, 53\% (104/196) were already including a section on housing in their current report, and 14 said that they would be in the future. Table IV shows the main reasons for non-inclusion.

Links with housing organisations - Links with housing associations were reported in $21 \%$ (41/196) of districts. Other links-for example, with housing charities
TABLE IV-Reasons for not including housing in annual report

\begin{tabular}{lc}
\hline Reason & $\begin{array}{c}\text { No of } \\
\text { respondents }\end{array}$ \\
\hline Links between housing and health too vague & 27 \\
No time & 25 \\
No manpower & 23 \\
Insufficient information available & 17 \\
No interest locally & 12 \\
Not a public health role & 12 \\
No space & 9 \\
Other priorities & 9 \\
Housing and health unrelated & 6 \\
Housing not a local problem & 5 \\
\hline Total responses & 145 \\
\hline
\end{tabular}

*Some of 92 respondents gave more than one reason.

and community groups - were uncommon. The main reason reported for existing links was to facilitate provision of housing to groups with special needs.

Specific services for the homeless - These were provided in $16 \%(32 / 196)$ of districts; in 23 this entailed specific medical care-for example, general practitioner sessions or a designated health visitor, in six the provision of shelter, and in three targeted information about health services. Such provision varied from $5 \%$ $(2 / 42)$ in rural districts to $50 \%(9 / 18)$ in inner city districts.

Health for all and healthy cities groups - These groups were reported in $52 \%(102 / 196)$ of districts, and in all cases a public health physician was involved. Their existence varied significantly by type of district: rural $30 \%(13 / 42)$, suburban $39 \%(7 / 18)$, mixed urban $59 \%$ (44/74), urban-rural $67 \%(27 / 40)$, and inner city $83 \%$ $(15 / 18) \quad\left(\chi^{2}=28 \cdot 2, \mathrm{df}=4, \mathrm{p}<0.001\right)$; the existence of a group was also positively related to whether housing was regarded as a local health problem or not $\left(58 \%(58 / 100) v 38 \%(33 / 87), \chi^{2}=6 \cdot 7, \mathrm{df}=1, \mathrm{p}<0 \cdot 05\right)$.

\section{Discussion}

This survey aimed at establishing the views of directors of public health on the importance of housing as a public health issue; the response rate of $89 \%$ was high and the findings are likely, therefore, to be representative, although the questionnaire method provides only a broad overview.

In half the districts housing was considered to be a major problem for the health of the local population, with respondents from inner city districts being significantly more concerned. This, perhaps, reflects a generally held view that housing problems are a typically urban phenomenon; the English house condition survey ${ }^{11}$ and recent research on rural housing shortages, does not, however, support this view. ${ }^{12}$

The vast amount of time still put into allocating medical priority for public sector rehousing was surprising, particularly given the resource shortages in public health medicine and the recommendation in the Acheson report that such activity should stop. ${ }^{9}$ In fact, several directors queried its effectiveness. The medical priority system presumes that it is possible to define a purely medical need for public sector rehousing and that this need can be weighted between people and against other needs - for example, social needs such as overcrowding. At a time of dwindling public sector accommodation it is important that this "rationing" system is equitable, and, given the culture of medical audit, that any input from the medical profession is effective. The medical priority system, however, has been strongly criticised as being poorly coordinated, subjectively exercised, ineffective, and inadequately evaluated. ${ }^{13-16}$ If these claims are justified what then should be the role of public health physicians?

Inequity exists and stems from the variation in the assessment policies of local authorities, ${ }^{1317}$ com- 
pounded by a system led by demand and the problem of variation in defining need. ${ }^{18}$ The system is ineffective in producing rehousing ${ }^{1319}$ and does not discriminate between those with and without ill health..$^{2021}$ Moreover, there are few studies to suggest that rehousing leads to improved health..$^{20}$ The medical priority system is inevitably inefficient in its use of medical resources. ${ }^{22}$ These findings, however, do not mean that there is no need for a rehousing system which explicitly takes account of medical factors, particularly as in practice most applicants are elderly and suffer from major chronic disorders, such as cardiovascular disease and osteoarthritis. ${ }^{2324}$ Adverse housing conditions for such patients can often lead to increased handicap, and rehousing may justifiably be regarded as part of rehabilitation. ${ }^{192+}$ In such cases a multidisciplinary approach may be more appropriate, comprising input from medical, social service, and housing sectors, which would be able to consider alternative options for people. Public health physicians do not have the training for such individual assessments, a more relevant background being rehabilitation medicine.

An important group affected by the rehousing process are "priority care" groups, such as the severely physically disabled, who are conventionally considered to have "special" housing needs. Overall, the directors reported little direct involvement in joint care planning teams for such groups, although housing for these groups was the second commonest housing problem stated. Housing associations are now increasingly expected to replace local authorities in providing housing for such people. Yet only a fifth of districts reported links with housing associations. Morris has shown that current housing policy for priority care groups is chaotic, with local authorities lacking data on the prevalence of disability and even on the availability of suitable accommodation. ${ }^{25}$ Very poor links between sectors were also found. When implemented, the NHS and Community Care Act 1990 will give local authority social service departments the responsibility for meeting the social needs of priority care groups, but the success, or otherwise, of this policy will to a large extent depend on the provision of suitable housing. ${ }^{2526}$ The act does not consider how this can be achieved. Public health advocacy has, therefore, a potentially important role in the effective matching of supportive housing with identified need.

In over half the districts housing issues were currently, or would be, included in the annual public health report. A substantial proportion of those not including housing issues stated that this was due to time or resource shortages. Such reports resurrect the annual reports of the former medical officers of health and are intended to report on the health of the local population. ${ }^{10}$ They provide a means to begin public health advocacy, and the evaluation of their impact on housing policies should become part of the audit of public health medicine.

The rising number of homeless people, both the single roofless and those placed in temporary accommodation, is a major housing problem. These groups are at risk of mental and physical ill health and face difficulties of access to primary care and elective hospital services, ${ }^{2728}$ and the temporary homeless are heavy users of hospital emergency services. ${ }^{29}$ Our present survey, however, did not show any systematic activity on homelessness, although several inner city districts had set up special services.

We found that the existence of multisectoral health for all or healthy city networks was related to whether housing was regarded as a problem for health. This is encouraging given the WHO's position; over $40 \%$ of districts, however, currently lack such groups.

The inequity and the mismatch between the need for and the supply of decent and affordable housing is likely to get worse given the current disarray of national housing policy. ${ }^{57}$ What are the implications for public health physicians and other health sector professionals? This survey shows considerable activity and concern, but current efforts are mainly, though not exclusively, channelled into medical priority assessments. To fulfil the advocacy role proposed by the WHO, the following could be considered for a new agenda for housing and health.

(1) Annual health reports could be used to highlight the effects of housing on the health of the local population using local and national sources of routine information and supplemented by ad hoc surveys; systematic monitoring of local housing by local authority environmental health officers might provide one useful database.

(2) The participation of public health physicians in determining medical priority for rehousing should be reassessed. It is debatable whether their participation should continue, especially given the resource constraints of the profession. If it does, criteria and objectives for rehousing should be established and the effectiveness of the process regularly evaluated. Any medical priority system should also include standardised procedures for involving general practitioners and hospital consultants. A more effective role for public health physicians, however, might be to establish or improve existing multisectoral links with local authority housing, social service, and environmental health departments, housing associations, and voluntary and community groups. Through such links the physicians could provide and interpret underlying epidemiological information and try to influence local housing policy towards appropriate provision for all, especially for priority care groups and the homeless. ${ }^{30}$

(3) The training of public health physicians and other doctors, especially general practitioners, should include an understanding of housing policy and the effects of poor housing on health. Likewise, there could be a greater health input into the training of local authority housing and social services staff.

(4) Nationally, data on the adverse effects which housing shortages and poor quality housing exert on health could be used to advocate a housing policy which promotes the public health; an important aim for such a healthy housing policy would be the establishment of health standards for house building.

Concern over the state of housing in the United Kingdom is not specific to public health physicians; other medical specialties, the wider public health movement, and people who are inadequately housed or homeless have as much, or greater, legitimate concern for establishing a health promoting housing policy. The present proposals should be regarded as part of this wider movement, uniting professionals with the communities they serve. ${ }^{30}$

We thank all the directors of public health who took part in the survey, the Health and Housing Working Party, Professor Jocelyn Chamberlain, Rhiannon Walters, Sally D'Sa, and Michele Richards for their help.

\footnotetext{
1 Ormandy D. Historical development of housing hygiene policy. $f R$ Soc Health 1987;107:39-42.

2 McKeown T. The role of medicine-dream, mirage or nemesis? London: Nuffield Provincial Hospitals Trust, 1976.

3 World Health Organisation, Regional Office for Europe. Targets for health for all by the year 2000. Geneva: WHO, 1985.

4 Department of the Environment. Housing and construction statistics 1978-88. London: Department of the Environment, 1989.

5 Niner P. Housing needs in the 1990s. London: National Housing Forum, 1989. 6 Department of the Environment. Homelessness statistics. London: HMSO, Depart 1988.

7 Morris JN. Inequalities in health: ten years and little further on. Lance 1990;36:491-3.

8 World Health Organisation. Health principles of housing. Geneva: WHO, 1989 9 Committee of Inquiry into the Future Development of the Public Health Function. Public health in England. London: HMSO, 1987.
} 
10 Department of Health. Health of the population: responsibility of health authorities. London: Department of Health, 1988. (HC(88)64.

11 Department of the Environment. English house conditions survey 1986. London HMSO, 1988

12 Clark D. Affordable rural housing; need and supply. Cirencester: Action with Communities in Rural England, 1990.

13 Gray JAM. Housing, health and illness. BMF 1978;277:100-1.

14 Parsons L. Medical priority for rehousing. Public Health 1987;101:435-41. 15 Lowry S. Housing for people with special needs. BMf 1990;300:321-3.

16 Prescott-Clarke P, Allen P, Morrissey C. Queuing for housing: a study of housing waiting-lists. London: HMSO, 1988.

17 Thomas HF, Yarnell JWG. Housing, health and illness. BMJ 1978;ii:358-9.

18 Kohli HO. Medical housing lines. BMY 1986;293:370-1.

19 Howells EL. Housing lines. BM 1 1984;288:201.

20 Eow PJ Pack JM A pr. BMJ 1984,288:201. on the grounds of mental ill-health. 7 Chronic Dis 1986;39:221-7.

21 Maclennan WJ, Grant J, Forbes B, Uruquart JM, Taylor-Brown $O$. The relevance of health to rehousing in old age. Health Bulletin 1982;41:181-7.

22 Fisk MJ. Medical assessments and priority for housing. Health Bulletin 1982:42:92-6.
23 Cole O, Farries JS. Rehousing on medical grounds-assessment of its effectiveness. Public Health 1986;100:229-35.

24 Gardner PA, Troop PA. Medical priority for rehousing. Housing 1981;17:20-1. 25 Morris J. Our rights, our homes: housing for disabled people. London: Shelter,

26 Secretaries of State for Health and Social Security, Wales, and Scotland. Caring for people: community care in the next decade and beyond. London: HMSO, 1989

27 London Food Commission, Maternity Alliance, SHAC, Shelter. Prescription for poor health. The crisis for homeless families. London: London Food Commission, Maternity Alliance, SHAC, Shelter, 1988.

28 Health Visitors Association and the General Medical Services Council of the BMA. Homeless families and their health. London: BMA, 1988.

29 Victor C, Connelly J, Roderick P, Cohen C. The use of hospital services by homeless people in an inner London district. BMF 1989;299:725-8.

30 Housing and Health Working Party, Faculty of Public Health Medicine. Housing or homelessness: a public health perspective-draft report. London: Faculty of Public Health Medicine, 1990.

(Accepted 12 Nonember 1990 )
Contributory benefits

Retirement pension Widow's benefit Unemployment benefit

Sickness benefit

Invalidity benefit

Maternity allowance

Non-contributory benefits

Child benefit

One parent benefit

Attendance allowance

Invalid care allowance

Mobility allowance

Severe disablement

allowance

Industrial injury benefit

Statutory sick pay

Statutory maternity pay

Means tested benefits

Income support

Housing benefit

Community charge benefit

Family credit

Social fund

Essential Rights,

94 Chaworth Road,

Nottingham NG2 7AD

Simon Ennals, consultant in

welfare law

Written in association with the Child Poverty Action Group

This is the fifth of 10 articles

BMf 1991;302:160-2

\title{
Understanding Benefits
}

\section{Benefits for people incapable of work}

\author{
Simon Ennals
}

The social security benefits that doctors come into contact with most frequently are those where a patient requests a "sick note" to show he or she is incapable of work. Some doctors resent this role of gatekeeper to the social security system, arguing that it gets in the way of their relationship with their patients. Doctors may feel pressurised to sign sickness certificates when they think them unjustified, and patients may resent a doctor's refusal to provide one, which then deprives them of benefit for themselves and their family. By developing an understanding of the benefit rules, however, and how the law interprets "incapacity," doctors can be in a powerful position to help patients to obtain their proper benefit rights and to protect them from being forced back into the labour market when their health and fitness may not justify this.

\section{What is incapacity for work?}

To qualify for sickness and invalidity benefits, the severe disablement allowance, and, in some cases, the disability premium for income support and housing benefit a patient has to show that he or she is "incapable of work by reason of some specific disease or bodily or mental disablement." Normally there is no problem at the start of a claim. For the first six days patients complete a self certification form SCl. After that the adjudication officer will usually accept the standard Med 3 certificate from a general practitioner. Legally, however, patients have to prove, on the balance of probabilities, that there is no work which they can reasonably be expected to do, taking into account their age, education, experience, state of health, and other personal factors. Work means part time or full time work for which an employer would be prepared to pay or self employed work in some "gainful occupation."

The starting point therefore is that the patient must be suffering from a "specific disease or bodily or mental disablement." It does not matter if the cause of the condition cannot be definitely identified: the importance is the effect on the patient. Genuine anxieties, hysterical states, or depression can all count, however imprecise the cause. Normal pregnancy does not count as a disease or disablement, but conditions arising from the pregnancy, such as high blood pressure, are relevant. Domestic circumstances, such as childcare commitments, are not directly relevant. In some circumstances patients can be deemed incapable, if, for example, a doctor certifies that they should not work "for precautionary or convalescent reasons" in consequence of a disease or disablement.

Short term incapacity-In the early stages of sickness patients' incapacity is judged by looking at their ability to do their normal job. It would clearly not be reasonable to expect them to change jobs just because of a short term illness. After a time, however-often after four to six months on benefit - the Department of Social Security will begin to consider whether the patient is capable of any other type of work. Whether a job is still being held open for the patient may well be an important factor in determining when the field of possible jobs should be widened, as would be such issues as how close the person is to retirement and the likelihood of recovery within the near future.

Incapacity for work - The test is whether patients are capable of doing any particular job, not whether they can actually get such a job. The fact that a job may be in great demand and that the patient is unlikely to succeed in getting one is not relevant. The test of incapacity is supposed to be a very practical one. The Department of Social Security should look at people's capacities in relation to the demands of real jobs in the competitive world of business. So any job a patient could get only on compassionate grounds, or with an employer making special allowances, is not to be taken into account. In the same way, if a patient could do a job only after extensive retraining, or with special adaptations to buildings or equipment, then it should be disregarded. The test is of the patient's capabilities now, rather than what they might be if certain conditions were to be satisfied. The emphasis on the economic realities of the world of work in the test of incapacity is particularly relevant to patients who may have an intermittent disability. A social security commissioner said in 1979, "A person who because of intermittent disablement could perform the duties of paid employment only on an average of, say, three days out of a five day working week . . . could rightly be held to be continuously incapable of work." This is because if patients cannot predict when they will be fit for work most employers would not take the risk of taking them on.

In summary, whether a patient is "incapable of work," and therefore warrants the issue of a sickness certificate, is primarily a medical question. Although initially it is enough to look at a patient's normal job, after a while the test is widened to include any job he or she could reasonably be expected to do. This must, 